\title{
Translators' Introduction
}

As a novelist, Tristan Garcia has received widespread recognition and awards, including the Prix de Flore. But it is his most recent philosophical work, Forme et objet: Un traité des choses, that secures his place as one of the most significant systematic philosophers in contemporary France.

Garcia's philosophical prose is lucid, in general presenting no special problems for the translator. However, a few key technical terms and phrases are so central to his system that any nonidiomatic English translation would invariably mislead the reader. Thus, explaining our translational choices requires some presentation of the system itself.

In English, 'comprehension' almost always denotes an epistemic state where one or more people understand some object or proposition. But this is not the case with respect to Garcia's use of 'comprébension'. For Garcia, one object comprehends another object whenever the second object can be said, in any way, to be contained in or encompassed by the first object. The closest English language usage occurs in mathematical set theory, where an axiom of comprehension defines new sets in terms of the properties of their members. But even the set-theoretic notion is merely one instance of Garcia's broader concept. Consider:

Comprehending is having something inside itself. Comprehending is also comprehending an element by being a set; comprehending one quality by being a substrata of qualities; comprehending someone by appreciating or paying attention to this someone; assimilating a way of thinking or an idea; having a part when one is a composite; or comprehending a temporal, historical, or evolutionary moment in a longer timespan. (i.iii.i, $\mathbb{S}$ I $\left.^{1}\right)^{1}$ 
The idea of comprehension is of central import to Garcia's system for two reasons. First, for Garcia being is nothing other than the inverse of comprehension:

Being is being comprehended. Comprehending is being been [être été]. The active sense of one is the passive sense of the other. (i.iii.i, $\mathbb{S}_{3}$ )

Second, combining this view of being with Garcia's liberal account of comprehension yields a rich ontology where anything that has a determination is something.

In Book I, Part I, Chapter I, Section I 5 Garcia produces a set of strikingly original arguments for ontological liberality. He considers in detail six distinct strategies that metaphysicians typically employ to deny that some putative kind of thing is really an object: logical, linguistic, epistemic, cultural, religious, and moral/political. Each strategy denies that something has what Garcia calls a 'minimum-of-whatness' (i.i.i. \$I6), that is, a minimum determination. ${ }^{2}$ Thus, for each case he opposes the claim that a particular category does not pick out objects by attending to how determinations are made within objects of that category. For example, in response to the logician who denies that there are true contradictions, Garcia notes that we can differentiate contradictory entities; the squared circle is necessarily circular while the non-white white is not.

If he is successful at blocking a priori attempts to banish whole kinds of entities from the realm of objects, Garcia must still fight the type of reductionism that attempts a posteriori to explain away one kind of entity in terms of another. Such explanatory violence often proceeds from below, trying to reduce an object to the entities that compose that object:

Reductionism reduces what things are to what composes these things. Physicalist or materialist reductionism reduces things to the matter that composes them. Evolutionary or naturalist reductionism reduces a living organism to the evolutionary processes of which the living organism is a result. (i.iii.ii $\$ I I)$

Or they can proceed from above, explaining away the object in terms of things that the object helps compose:

Other types of reductionism capture the chain of being from the other direction, and reduce a thing to what it is, that is, to what it is 
in. Social reductionism reduces a social element to its function in the social whole. Historical reductionism reduces a historical event to the history within which it obtains its place. (i.iii.ii $\mathbb{\text { II }}$ )

Following Graham Harman's usage, ${ }^{3}$ we can say that Garcia's system is an instance of 'object-oriented ontology' because his central ontological operations are motivated by the attempt to understand what objects must be like if they are to resist reduction from below and from above. Unlike Harman, though, Garcia actually defines the objectivity of an object in terms of this very resistance.

A thing is nothing other than the difference between that which is in this thing and that in which this thing is. Unless one guarantees this double sense, there are no thinkable things. Every reductionist who claims to deduce that which this or that thing is from that which composes this or that thing only succeeds in dissolving the very thing that they claim to account for. (I.)

Articulating the way this double sense plays out with respect to objects of human interest (beauty, truth, goodness, death, etc.) will be the central motif of Book II. However, before engaging in regional ontology, Garcia's differential model of being must immediately face a question. If an object is the difference between that which it comprehends and that in which it is comprehended, can an object comprehend itself?

The negative answer to the possibility of what Garcia calls 'compactness' (le compact) is deceptively simple. If an object just is the difference between that which comprehends it and that which it comprehends then nothing can comprehend itself. 'Difference' here is like subtraction. Since, prima facie, there is no difference between an object and itself, ${ }^{4}$ an object for Garcia is just the difference between that which the object comprehends and that which comprehends the object, so a self-comprehending object would subtract itself from itself and be nothing.

This answer is deceptively simple because while there are clearly no compact objects in Garcia's ontology, 'compactness' also names a tendency towards which some things move. And Garcia enumerates central instances of this tendency: philosophers trying to think of things as 'in themselves', the shy person's attempted withdrawal into herself, the saint who would merge 
with the universe, the introspective psychologist pursuing a perfect kind of self-consciousness, and so on. Objects tend towards the compact, but never reach it, because doing so would result in annihilation.

Readers of Book II will find out just how much of the human condition rests on this impossibility. Indeed, it is so central that Garcia uses the concept to articulate his anti-reductionism.

Reductionism consists in refusing to consider the irreducibility of that which is a thing to that which it is.

The cost of reductionism is the conception of a compact point. (i.iii. ii $\$$ II)

Reductionism effaces the difference between that which is comprehended and that which is comprehending, rendering the object itself, which is this difference, nothing.

After articulating the negative grounds for rejecting reductionism, Garcia still must construct a positive metaphysics that explains how objects resist their own annihilation. At the very outset of this task he must confront two more categories at opposite ends of being: no-matter-what and something-other-than-athing. These are the most technically demanding concepts in the book.

Translation is difficult here because (just as Heidegger did with 'Nichts') Garcia uses the French phrase 'n'importe quoi' in both a quantificational ('for any $\mathrm{x}$ ') sense and in a more name-like sense (analogously to Heidegger's 'the anything'). Failure to attend to the way this is licensed by his ontology will lead the English reader to see inconsistencies in the text that are not there and also miss the philosophical depth of Garcia's discussion.

The English language reader will be prone to think there is a contradiction in part because, on the one hand, Garcia claims that something can never be no-matter-what - that nothing can be nomatter-what. For example:

Something is never no-matter-what. I could not find something in the world which would be no-matter-what. (i.i.i \$9)

That nothing is no-matter-what means that there does not exist any object, event, god, or idea that would be 'no-matter-what'. (i.i.i \$IO)

But then, on the other hand, no-matter-what can be something: 
Nonetheless, no-matter-what is not nothing. On the contrary, nomatter-what - that is to say, 'equally this or that or any other thing' - is something. (i.i.i $\$ 13$ )

Garcia is saying both that no-matter-what is something and that nothing is no-matter-what. And he continues:

From this we can claim that it is incompatible to be something and to be no-matter-what. Everything which is not no-matter-what is something. (i.i.i $\$$ I 6 )

Again, how can one simultaneously maintain (I) that it is incompatible to be something and to be no-matter-what, and (2) that no-matter-what is something?

To answer this question we must go back to Garcia's concept of comprehension. For Garcia, any object that includes another in any way can be said to comprehend that other object. Thus:

The first major consequence of interpreting 'being' as the inverse of 'comprehending' derives from the product of an 'antisymmetric' relation. It may seem that being is the sign of a symmetric identity relation: if $a$ is $b$, then $b$ is $a$. No! Being is antisymmetry par excellence: if $a$ is $b$, then $b$ cannot be $a$. Being means nothing other than this unidirectionality [ce sens unique]. (i.iii, p. I24)

By carefully attending to comprehension's antisymmetry we can show the seemingly contradictory claims to be consistent.

First, consider the claim that nothing is no-matter-what. Here, take 'nothing' in the quantificational sense and no-matter-what as name-like. Thus, all things are such that they do not enter into the no-matter-what - or, equivalently, all things are such that the no-matter-what does not comprehend them.

Given that being is being comprehended, and that this is antisymmetric, if nothing is no-matter-what, then (for Garcia) nomatter-what is not nothing. This means, quantificationally, that no-matter-what is something.

Now let us recover our pre-Carnapian innocence and think of the quantificational phrase 'something' as name-like. To make this as clear as possible, talk of 'the something'. Then to say that no-matter-what is something is to say that no-matter-what 
enters into the something and that the something comprehends no-matter-what.

So let's consider the claim that no-matter-what is something with 'no-matter-what' understood quantificationally. Then, to say that no-matter-what is something is to say that anything is something, or as he sometimes puts it 'anything can be something'. Like Meinong, or perhaps more so, when Garcia says 'anything' he really means anything. ${ }^{5}$ For Garcia, any existent or nonexistent, possible or impossible, imaginary or real, consistent or inconsistent thing is a thing.

But why should one accept this aspect of Garcia's ontology? Remember that for Garcia to be is to be determined. From this, everything that he says about the no-matter-what follows logically. All one must do is consider an entity that lacks all determination, and note that lacking all determination is itself a determination. For Garcia, the no-matter-what names precisely this determination of lacking all determination. Consider a representative passage:

When this clementine is something, it is not that clementine or something else. No-matter-what, we have said, is this or that or its opposite or something else. No-matter-what is something, anything.

A clementine is not this or that or its opposite or anything else. It matters that a clementine be something, that is, that it can be this or that, but that it absolutely cannot be this or that or anything else. If a clementine is no-matter-what, then it is not a matter of a clementine. (i.i.iii $\$ 7$ )

For a clementine to be something it must be determined in some way, but no-matter-what's only determination is that it lacks all determination.

In order to articulate what is arguably the most resolutely anti-reductionist metaphysical system in the history of thought, Garcia puts forward the bold Meinongian claim that anything (no-matter-what) is something. While critiquing specific forms of reductionism inconsistent with this claim, he argues that all that is necessary for being something is possessing some determination. But then what about the concept of just being anything? For this concept to be maximally inclusive it must lack any determination whatsoever. But 'lacking any determination whatsoever' is itself a determination. So it would seem to both lack and possess determinations. 
One might say that this no-matter-what is itself thus a contradictory entity, but Garcia's model of being provides a way out of the paradox. Consider all of the things that lack all determinations. By describing the collection in this way, we provide a determination, so everything in this 'collection' is both determined and not determined. So, on the assumption that this is a contradiction we should reject, we now know that nothing is in this collection. But now we have a 'thing' such that nothing is (in) this thing! Moreover, this thing is something, as it has a determination, being the collection of all things that have no determination.

Enthusiasts of mathematical set theory will recognise here the sense in which no-matter-what, qua thing, is similar to the empty set. However, the derivation (which one can fully formalise using an unrestricted second-order comprehension axiom $)^{6}$ of this object is, as far as we know, entirely original with Garcia.

With all of this on the table, we can see how Garcia's radical anti-reductionism thus rests on two key claims: (I) no-matter-what can be something, and (2) an object is just the difference between that which it comprehends and that which comprehends it. But if this were the end of the story, Garcia's ontology would easily fall prey to the traditional problem faced by relationist metaphysicians such as A. N. Whitehead, Bruno Latour, and the British Hegelians (Bernard Bosanquet, F. H. Bradley, and J. M. E. McTaggart). Simply put, if the identity of an object depends on its relations to other objects, then one or two things typically follow. The first danger, presented as a virtue by Whitehead and Latour, ${ }^{7}$ is that the metaphysics is inconsistent with an object being the same object through any kind of change. Consider Garcia's differential model as applied to the translators of this book. When we first entered the swamps of Louisiana, new things comprehended us. But then if we are merely the difference between the objects that compose us and those things that comprehend us, we became new objects the first time we were subject to the stare of a preternaturally still alligator lurking among the bald cypress knobs.

The second danger, presented as a virtue by the British Hegelians, ${ }^{8}$ is in tension with the first. If the first danger is that the ontology is committed to too many objects existing (the translators prior to moving to Louisiana and the translators in Louisiana as separate objects), the second is that the ontology is only committed to one object. For, if the identity of every object is determined by its relation to all other objects, whose identity is also determined by 
their relations to everything else, then the only thing with intrinsic properties is the totality of these relations.

Garcia's claim that each thing is alone in something-other-thana-thing is his third most important just because its truth, along with his philosophy of time, helps one navigate between the Scylla of Whitehead's actual occasions and the Charybdis of Bradley's absolute. While objects just are differences, for Garcia these very differences are independent things alone in the world.

To be in the world is to be outside itself in something-other-than-athing. Every thing enters, as an object, into a manifold of 'big things' ['grosses choses']: relations, domains, definitions, determinations, sets, and so on. Every thing always belongs to these big things with other objects. But insofar as every thing enters into things, it also enters into something-other-than-a-thing - into that which is not a thing, which we shall call the world. The world is not a reality that pre-exists things, of which one could say that the world is this or that. The world is nothing other than what every thing enters into equally. The world is what enters into nothing. (i.i.iii)

We will not try here to assess whether Garcia's gambit is successful. ${ }^{9}$ Rather, we just note that its success would represent a fundamental advance in the history of metaphysics, a relational ontology which is both non-holistic and such that objects remain self-identical over time.

Why does Garcia call his world something-other-than-a-thing? As with no-matter-what's similarity to the empty set, we must again consider mathematical set theory. Garcia's world is just like a 'proper class' in some versions of set theory ${ }^{10}$ in that while things can be members of it, it cannot be a member of anything. But why is this? Since Garcia explicitly defends inconsistent objects, the normal mathematical reason that the set of all sets leads to contradiction via Russell's Paradox is not enough. ${ }^{11}$ No, the real problem is that a set of all sets would be a member of itself (since it is a set that contains all sets), and thus be compact. Since an object is just the difference between that which it includes and that which includes it, the set of all sets would actually be nothing. ${ }^{12}$

Book II is largely an extension and application of the ideas of Book I's pure ontology, developing regional ontologies of an astonishing number of discrete kinds of objects. In the context of 
what we've said here, two things should be noted. First, Garcia's attempt to avoid the Scylla of Whitehead's actual occasions is dependent on the philosophy of time articulated in Book II. Second, the manner in which the differential ontology is embodied in these kinds ends up obliterating the dialectic between Nietzsche and Hegel that philosophers such as Andrew Bowie find to have been reiterated over and over again in contemporary continental philosophy. ${ }^{13}$ If Garcia is successful, then we have principled grounds for refusing final Hegelian syntheses without in any way giving in to Nietzsche's anti-metaphysics. One must try to explain a phenomenon such as adolescence from below, following the history of biological explanations. One must also try to capture it from above, with progressive sociological myths involving adolescence and the adolescent. But adolescence itself actively resists its own compactness, its own annihilation through reduction, and one cannot understand adolescence itself unless one understands the history of this resistance.

While Garcia must introduce other productive technical concepts (particularly that of intensity) to make sense of the full range of topics discussed in Book II, the resistance predicted by the differential model is a constant. And the contradictions that result between explanations from above and below, and from successive explanations trying to catch up with the object's resistance, are never resolved. Pace contemporary Nietzscheanism, this has nothing essential to do with our epistemic or conceptual limitations, real as those may be. That is, objects really are such agents of resistance. But as readers of Garcia's Coda will come to realise, it is not clear whether there is any consolation here. There is never a Hegelian synthesis. Nor could there be ...

$$
\begin{array}{r}
\text { Mark Allan Ohm and Jon Cogburn } \\
\text { Baton Rouge, Louisiana } \\
\text { June 20I } 3^{14}
\end{array}
$$

With the exception of the notes that follow, all notes are Garcia's own unless otherwise indicated in brackets. Garcia's sources were checked with their English-language originals, or translations when available. Some translations have been modified. All translated citations that did not have English translations at the time of writing are the translators' own. French terms occasionally appear in brackets in the body of the text, and certain terms and phrases 
were corrected or clarified at Garcia's request. Bilinguals may consult the original for comparison.

\section{Notes}

I. We read '(i.iii.i, $\mathbb{S I}_{4}$ )' as 'Book I, Part III, Chapter I, Section I4'. With one exception, each chapter in Book I begins with numbered sections, followed by one to three sections of commentary. The chapters in Book II do not begin with numbered paragraphs, and are divided into named sections. So '(i.i.iii)' will cite material in the post-numbered commentary in Book I, Part I, Section III, and '(ii. ii.A)' will cite material in Book II, Chapter II, Part A. For material in the Introduction we use '(I.)'.

2. As with the example of a clementine that follows, Garcia makes this point very clearly elsewhere. See Garcia's 'Crossing Ways of Thinking: On Graham Harman's System and My Own'.

3. See especially Harman on over- and undermining in the opening sections of The Quadruple Object as well as the discussion of speculative realism and object-oriented philosophy in the translators' own 'Actual Qualities of Imaginative Things: Notes Towards an ObjectOriented Literary Theory'. Garcia explicitly mentions Harman in the Introduction and then discusses his philosophy much more extensively in 'Crossing Ways of Thinking: On Graham Harman's System and My Own'.

4. We would be remiss if we did not note that this is a little too quick. In Chapter XII of Book II, Garcia's account of beauty allows things to be more or less themselves, with the beautiful object being maximally itself.

5. However, it should be noted that Garcia distances himself from Meinong and various neo-Meinongian currents. See Garcia's 'Après Meinong. Une autre théorie de l'objet'.

6. The translators do this rigorously in 'Garcia's Paradox', presented at the 2013 Notre Dame Translating Realism conference. Secondorder versions of the standard natural deduction introduction and elimination rules are required. For example, the derivation from the fact that an arbitrary object lacks all determinations $(\forall P \neg P(\mathrm{~b}))$ to the conclusion that it does have a determination $\exists P(P(b))$ is simply an instance of second-order existential introduction.

7. For a rather profound discussion of this point with respect to Latour, see Harman's Prince of Networks: Bruno Latour and Metaphysics. In 'Object-Oriented France: The Philosophy of 
Tristan Garcia', Harman explicitly raises the worry with respect to Garcia.

8. Bradley's Appearance and Reality is perhaps the canonical text arguing in this fashion. Much of what is still called 'deconstructionism' in American humanities departments is just Bradley's arguments about the individuation of objects applied to word meanings.

9. Again, we note Harman's worry about whether Garcia is successful. The issues are deep, and as we go on to remark above, crucially involve the interplay between Garcia's philosophy of time and the formal model of things alone in the world.

Io. NBG (Neumann-Bernays-Gödel) set theory quantifies over proper classes. However, even in the more standard Zermelo-Fränkel set theory, sentences with free variables must be (meta-linguistically) thought to name proper classes. For a withering critique of both forms that has strong overlap with Garcia's defence of true contradictions, see Graham Priest's In Contradiction and Beyond the Limits of Thought.

I I. To be clear, Quine's 'New Foundations' has a universal set and is probably consistent. However, if Priest's arguments against the restriction strategies of standard set theory are valid they would also apply against the kind of type-theoretic restrictions in set theories of this type. In this context, one must also consider the tradition of non-well-founded set theory, which avoids Russell's Paradox via restricted comprehension while still allowing sets to be members of themselves.

I2. There are real opportunities for the ambitious formal ontologist here. Since Garcian objects are in part determined by the things that comprehend them, a Garcian set theory would be inconsistent with the standard axiom of extensionality (cf. Nicholas Goodman's 'A Genuinely Intensional Set Theory'). In addition, one would need to look at formal accounts of mereology, since on the issue of unit sets not being identical with their members, versus the way mereology treats join, Garcia's comprehension is much more mereological. There are axiomatisations of mereology where the join relation is irreflexive, antisymmetric, and (unlike set-theoretic membership) transitive, exactly as is Garcia's comprehension. A successful formalisation would capture the important truths of comprehension, and also shed light on the relation between standard set theories and the new intensional mereology. We don't know whether the formalism would need to be dialetheist just because it is possible to be a dialetheist, but (analogous to the manner in which one might 
view glut semantics, perhaps via a guerilla reading of Priest's notion of classical recapture) to avoid substructuralism by taking true contradictions to impose pragmatic restraints on the use of consistent formalisms.

I3. See Bowie's Schelling and Modern European Philosophy. Recent English language philosophy that genuinely enters into Habermasian dialogue with the German Idealists follows Bowie in critiquing recent philosophy as mere recapitulations of Nietzsche's complaints, but pace Bowie are not ready to consign metaphysics to the wide Sargasso Sea of positivism and phenomenology. See especially Iain Hamilton Grant's Philosophies of Nature after Schelling and the object-oriented Hegel developed by Robert Stern in such works as Hegel, Kant, and the Structure of the Object and Hegelian Metaphysics.

I4. We would like to thank Ridvan Askin, Eric Bjella, Graham Bounds, Levi Bryant, Emily Beck Cogburn, Jenny Daly, Paul John Ennis, Tristan Garcia, Patrick Gamez, Fabio Gironi, Graham Harman, Adrian Johnston, Carol MacDonald, Rebecca Mackenzie, Raphaël Millière, Louis Morelle, Leah Orth, and Dawn Suiter. Orth served as Cogburn's research assistant during the summer of $20 \mathrm{I} 2$ and helped check the initial translation of the book's Introduction. Beck Cogburn, Garcia, and Harman each read and annotated complete drafts. Daly, MacDonald, Mackenzie, and Harman have been helpful and attentive throughout. Garcia himself has been unfailingly helpful and solicitous. An unexpected source of joy has been just how much philosophy we have personally learned from Harman and Garcia while thinking through their responses to our missives concerning the translation. Our greatest hope is that this is reflected appropriately both here and in what follows. 